\title{
MEMÓRIA COLETIVA E LEMBRANÇAS INDIVIDUAIS A PARTIR DAS PERSPECTIVAS DE MAURICE HALBWACHS, MICHAEL POLLAK E BEATRIZ SARLO
}

\author{
Fábio Daniel Rios ${ }^{1}$
}

\begin{abstract}
RESUMO: Nesse artigo, discuto a relação entre memória coletiva e memória individual segundo três perspectivas distintas. Maurice Halbwachs é o fundador dos estudos sobre a memória na área das ciências sociais, concebendo-a como um fenômeno inteiramente coletivo. Pollak retoma e problematiza essa perspectiva, apontando o caráter negociado da memória e a importância da agência individual para a sua formação. Por fim, Sarlo indica os limites da subjetividade como fonte de conhecimento e destaca o caráter discursivo da constituição mnemônica. Em suma, a memória não é totalmente coletiva, nem inteiramente individual: estrutura e prática se entrelaçam no processo de construção das recordações.
\end{abstract}

PALAVRAS-CHAVE: Memória coletiva; memória individual; poder de agência.

Recebido em: Agosto, 2013

Aceito em: Novembro, 2013

Para citar este artigo:

RIOS, FÁBIO; "Memória coletiva e lembranças individuais a partir das perspectivas de Maurice Halbwachs, Michael Pollak e Beatriz Sarlo". In: Revista Intratextos, 2013, vol 5, no1, p. 1-22. DOI: http://dx.doi.org/10.12957/intratextos.2013.7102

\footnotetext{
${ }^{1}$ Doutorando do Programa de Pós Graduação em Ciências Sociais da UERJ, bolsista CAPES. Email: fabiodanielsr@gmail.com.
} 


\section{Introdução}

Nesse artigo, discuto a relação entre memória coletiva e memória individual a partir das obras de três autores fundamentais para esse campo de estudos: Maurice Halbwachs, Michael Pollak e Beatriz Sarlo. Os dois primeiros podem ser considerados nomes clássicos da literatura sociológica sobre a memória, enquanto Sarlo é uma autora contemporânea, ainda em atividade, cuja obra vem trazendo importantes questionamentos sobre o tema. Desse modo, analiso e comparo as definições de cada um desses autores sobre o fenômeno da memória: como ela se forma, que tipo de função ou trabalho ela realiza, que tipo de conhecimento sobre o passado ela nos permite construir.

$\mathrm{Na}$ medida em que todos esses autores definem a memória como um fenômeno coletivo, minha intenção é saber que espaço eles reservam para as memórias individuais. Ou seja, na visão desses autores seria indiscutível o fato de que a memória apresenta uma dimensão social ou coletiva, no entanto, que lugar o indivíduo ocuparia nesse processo? Existem lembranças puramente individuais, ou o sujeito se encontra completamente submetido aos ditames da sociedade? O indivíduo é capaz de formar memórias particulares? Ele participa da formação das memórias dos grupos? Nesse caminho, a relação entre memória e história também se mostra relevante, pois coloca em discussão a formação social da experiência subjetiva e nos ajuda a compreender como a relação indivíduo-sociedade se manifesta no processo de constituição das lembranças.

\section{Maurice Halbwachs e o caráter coletivo da memória}

Maurice Halbwachs é o responsável pela fundação do campo de estudos sobre a memória na área das ciências sociais. Na década de 1920, ele lança o livro Les cadres sociaux de la mémoire (Os quadros sociais da memória), erigindo um novo objeto de pesquisa para a sociologia. Com esse gesto, porém, não era apenas a sociologia que ganhava um novo tema de investigação; podemos dizer que a memória também encontrava uma nova casa, um novo campo de reflexões para ser pensada, discutida e redefinida. Afinal, no âmbito do pensamento ocidental, a memória já havia ocupado a reflexão de importantes pensadores desde a antiguidade, incluindo filósofos como Aristóteles, Santo Agostinho e Henry Bergson (Santos, 
2003). Este último exerceu grande influência sobre o pensamento de Halbwachs, contribuindo ainda para a discussão sobre a memória em outras disciplinas.

Outra influência fundamental para o pensamento de Halbwachs foi a obra do sociólogo francês Émile Durkheim. Ao lado de Weber e Marx, Durkheim é apontado como um dos fundadores da sociologia, tendo sido o responsável pela constituição de uma das matrizes fundamentais da disciplina: o funcionalismo. Com o intuito de delimitar a especificidade da sociologia como um campo autônomo de conhecimento, diferenciando-a de áreas como a Psicologia e a Filosofia, Durkheim (1984) definiu os "fatos sociais" como os objetos próprios de reflexão da nova ciência. Os "fatos sociais" teriam uma existência objetiva fora das consciências individuais, atuando de modo coercitivo sobre elas. Na abordagem durkheimiana, o comportamento do indivíduo é determinado por fatores que se impõem a ele desde o meio externo, tendência seguida por Halbwachs em sua abordagem sobre a memória.

Halbwachs costuma ser associado à segunda geração da escola sociológica francesa, grupo ao qual também pertenceram autores como Marcel Mauss, Robert Hertz e até mesmo Durkheim, se considerarmos a fase final de sua produção. Após um primeiro momento mais extremo de afirmação da sociologia como disciplina autônoma, esses autores procuravam agora tornar a abordagem funcionalista um pouco mais complexa e matizada. Nesse sentido, eles aprofundaram a discussão sobre a relação indivíduo-sociedade, sem abandonar o determinismo da primeira geração, mas tentando mostrar o desenvolvimento da "estrutura" no plano das "ações individuais". Esses autores destacaram também a dimensão simbólica da vida social, concebendo os códigos sociais como uma espécie de linguagem.

No livro Os quadros sociais da memória, Halbwachs lança as bases para a constituição de uma abordagem sociológica sobre o ato de rememoração. Nessa obra, ele realiza algo semelhante ao que Durkheim havia feito no livro O suicídio (2000), procurando atestar a objetividade das lembranças como fenômeno coletivo através de uma abordagem próxima da morfologia social (Santos, 2003). No presente trabalho, contudo, concentraremos nossa atenção sobre outra obra fundamental de Halbwachs: A memória coletiva (2006). Lançada postumamente na década de 1950, ela tem um caráter ensaístico, dando continuidade 
à abordagem funcionalista iniciada na década de 1920, mas deixando algumas lacunas que permitem novas interpretações sobre o fenômeno da memória.

Ao longo das obras de Halbwachs, sobressai a noção de que a memória consistiria num fenômeno eminentemente coletivo. Ou seja, ao invés de ser um fato puramente individual - como era defendido pela filosofia, pela psicologia e pelo senso comum da época -, a memória seria uma construção social, constituindo-se a partir das relações mantidas entre os indivíduos e grupos. Essa é a tese central de Halbwachs, para quem a memória tampouco poderia ser concebida como um fenômeno puramente biológico, ou como uma mera reação fisiológica. A caracterização da memória como um fenômeno coletivo segue, portanto, a mesma fórmula tradicional que opõe a constituição do social aos planos do indivíduo e da natureza - fórmula que sustentou a especificidade da sociologia, num primeiro momento de sua formação.

No esquema analítico de Halbwachs, afirmar que a memória tem um caráter coletivo equivale a dizer que o indivíduo só é capaz de recordar na medida em que pertence a algum grupo social - ou seja, a memória coletiva é sempre uma memória de grupo. Assim, só é possível ao sujeito construir e acessar lembranças na condição de membro de um conjunto ou totalidade que o ultrapassa, não só em termos quantitativos, mas também em termos qualitativos. $\mathrm{O}$ indivíduo isolado não forma lembranças, ou pelo menos não é capaz de sustentá-las por muito tempo, pois necessita do apoio dos testemunhos de outros para alimentá-las e formatá-las. As memórias individuais se formam a partir da relação com o outro:

Recorremos a testemunhos para reforçar ou enfraquecer e também para completar o que sabemos de um evento sobre o qual já temos alguma informação. (Halbwachs, 2006, p.29)

É preciso que haja um mínimo de concordância entre as lembranças dos indivíduos para que elas possam se complementar, formando um patrimônio comum de recordações. A memória tem, portanto, um caráter relacional, formando-se na interação entre os indivíduos. Segundo Halbwachs, as lembranças mais difíceis de serem recuperadas são justamente aquelas relacionadas a eventos que vivenciamos sozinhos, pois nesses casos, não podemos 
contar com o auxílio de ninguém mais para mantermos vivas essas experiências em nossos pensamentos. Incomunicáveis, elas tendem a desvanecer.

Se, por um lado a memória é coletiva, por outro, somente o indivíduo é capaz de lembrar. Como afirma Halbwachs, em todo ato de memória se faz presente uma espécie de “intuição sensível”, que parece denotar a participação do indivíduo na formação das lembranças. No entanto, o sujeito não é nada mais que um instrumento das memórias do grupo, mesmo quando lembra individualmente:

\begin{abstract}
Nossas lembranças permanecem coletivas e nos são lembradas por outros, ainda que se trate de eventos em que somente nós estivemos envolvidos e objetos que somente nós vimos. Isto acontece porque jamais estamos sós. Não é preciso que outros estejam presentes, materialmente distintos de nós, porque sempre levamos conosco certa quantidade de pessoas que não se confundem. (Halbwachs, 2006, p.30)
\end{abstract}

A memória individual está contida no conjunto maior da memória coletiva, sendo apenas um fragmento ou uma visão parcial dos fatos vivenciados pelo grupo. Ela é mais densa, porém, menos abrangente do que a memória social. De modo geral, o indivíduo apenas materializa a ação de forças sociais que o ultrapassam. Para Halbwachs, o sentimento de liberdade e singularidade do indivíduo não passa de uma ilusão: a diversidade de comportamentos individuais pode ser entendida como o resultado das diferentes combinações de forças sociais sobre cada sujeito. Ou seja, cada indivíduo é como uma configuração específica criada pelo cruzamento de diferentes forças sociais concomitantes. O sujeito sofre, ao mesmo tempo, a influência de diversas correntes de pensamento coletivo, mas por não poder atribuir seu comportamento a nenhuma delas exclusivamente, passa a creditar a si mesmo a responsabilidade por seus atos, acreditando na possibilidade de agir de modo totalmente autônomo.

Mesmo quando constrói lembranças baseadas em experiências individuais, o sujeito precisa recorrer a instrumentos que lhe são fornecidos pelo meio social, tais como as idéias e as palavras. Só assim ele pode tornar sua experiência inteligível e comunicável, não só para os outros, mas também para si mesmo. O indivíduo absolutamente isolado não seria capaz de construir qualquer tipo de experiência, não sendo capaz também de manter qualquer tipo de registro sobre o passado. Porém, como vimos, na prática “jamais estamos sós”, pois estamos 
sempre imersos num mundo de símbolos socialmente construídos, que nos fazem sentir a constante influência da sociedade sobre nosso comportamento. A percepção individual é formatada por códigos sociais que funcionam como uma linguagem. Somente por meio da referência a um mesmo conjunto de símbolos, socialmente elaborados, os indivíduos podem dotar suas experiências de significados, e essa mesma condição também atua sobre a construção de visões sobre o passado. Nesse sentido, a memória é social porque, em última instância, toda forma de experiência também o é.

Segundo Halbwachs, as memórias individuais se constituem a partir de "quadros" fornecidos - ou impostos - pelo meio social. Esses são os chamados "quadros sociais da memória", que funcionam como pontos de referência para a construção subjetiva de lembranças. Eles determinam o que deve ser lembrado, esquecido, silenciado ou comemorado pelos indivíduos. A contextualização realizada pelos quadros sociais inclui, ainda, a padronização social do tempo e do espaço, dimensões fundamentais da experiência humana.

Na concepção de Halbwachs, a memória pode ser entendida como uma re-construção do passado realizada com o auxílio de dados do presente. Isso ocorre através de um processo de seleção, pois é impossível registrar tudo o que ocorreu num dado momento, não só no plano individual, mas também no plano coletivo. Assim, as visões construídas sobre o passado revelam mais sobre o momento presente do que sobre o passado que se pretende restituir. Nossas visões sobre o passado são incompletas, parciais e cambiáveis. Elas podem variar conforme a posição que ocupamos num determinado grupo e conforme mudam as relações desse grupo com outros meios. A participação dos indivíduos em variados grupos faz com que suas memórias se formem de modo fragmentário, como um mosaico.

A memória é, portanto, um tipo de relação que se estabelece entre o presente e o passado. Simbolicamente, ela é capaz de congelar o tempo por um instante, fornecendo uma imagem bem acabada sobre determinado momento de nossas vidas, permitindo que ele seja revivido de algum modo por nós. O tempo, no entanto, consiste também numa construção social. O modo como o percebemos é marcado por padrões e convenções coletivas que organizam a experiência dos indivíduos. Embora tenha uma dimensão subjetiva, a padronização do tempo é fundamental para a sincronização das ações individuais, permitindo o desenvolvimento da vida social. 
O mesmo ocorre com o espaço: cada grupo se relaciona com ele de modo particular, moldando-o à sua imagem e semelhança. A experiência subjetiva é mediada por convenções sociais, que condicionam sua orientação espacial. Os grupos fazem do espaço um espelho, no qual procuram projetar sua própria imagem. Ele serve de depositário para os valores e modos de vida dos grupos, materializando-os sob formas mais ou menos estáveis. Desse modo, a fixidez do espaço permite que os grupos possam objetivar suas memórias e identidades, como acontece no caso dos monumentos, prédios históricos e todo o patrimônio arquitetônico cultivado por determinado grupo.

A padronização do tempo e do espaço permite, portanto, a formação de memórias, que cumprem uma função social fundamental: elas contribuem para a manutenção e coesão dos grupos, na medida em que ajudam a produzir o sentimento de identidade entre seus membros. Segundo Halbwachs, o compartilhamento de memórias contribui para a formação de uma "comunidade de sentimentos". Por meio da memória, o grupo lança suas raízes no passado, assentando suas origens num momento distante e, muitas vezes, mítico. Essas memórias são objetivadas no espaço, conferindo materialidade e estabilidade ao modo de vida do grupo.

A relação entre memória e identidade faz com que Halbwachs estabeleça também uma associação entre memória e tradição. Para o autor, a memória não diz respeito simplesmente a uma experiência iniciada e concluída no passado, mas sim a algo que permanece vivo, animando os pensamentos e ações dos indivíduos e grupos no presente. Quando uma memória deixa de existir, isso significa que os laços sociais que a alimentavam - e que nela se alimentavam - já não existem mais, ou seja, foi o próprio grupo, outrora cultivador dessa lembrança, que deixou de existir. Nesse ponto, a memória se distinguiria da história, pois esta - enquanto disciplina acadêmica - corresponderia ao registro escrito de acontecimentos que já não se encontram mais vivos na memória de nenhum grupo. Para Halbwachs, a memória é vida, consiste numa visão interna do grupo sobre si mesmo e tem um caráter múltiplo, pois cada grupo cultiva um conjunto particular de lembranças. A história, por sua vez, é como um "cemitério" habitado por fatos que já morreram nas memórias dos grupos; trata-se de uma visão externa e racionalizada dos acontecimentos, que almeja à universalidade e, ao pretender ser de todos, torna-se propriedade de ninguém. Em suma, a história só é possível e só se faz necessária quando a memória-tradição já não existe mais. 


\section{Michael Pollak e o caráter negociado das memórias.}

Michael Pollak é outro importante artífice dos estudos sobre memória no campo das ciências sociais. Sua obra realiza um diálogo bem-sucedido entre áreas como a sociologia, a história e a psicanálise. Embora Halbwachs tenha iniciado a reflexão sobre a memória entre as décadas de 1920 e 1940, somente nos anos 1970 e 1980 sua obra seria redescoberta e revalorada, efetivando-se como um campo sólido de estudos sobre o tema. Dentre os autores que participaram desse processo, encontra-se Michael Pollak, num momento em que a história procurou encampar a memória como objeto de estudos e fonte de dados. Novas áreas de pesquisa surgiram nesse contexto, como a nova história, a história oral e a história do tempo presente. A seguir, analiso a obra de Pollak a partir de dois artigos importantes para a divulgação de sua obra no Brasil: "Memória e identidade social" (1992) e "Memória, esquecimento, silêncio" (1989).

Pollak traz importantes inovações para a abordagem sociológica da memória, mas não rompe, simplesmente, com a obra de Maurice Halbwachs. Ele é influenciado de muitas maneiras pela obra do sociólogo francês, e podemos dizer que as definições de memória de ambos os autores concordam em diversos pontos. Em linhas gerais, tanto Pollak como Halbwachs apontam a memória como um fenômeno coletivo, definindo-a como uma construção social. Por ser uma construção, a memória envolve um processo de escolha, sendo parcial e seletiva. Ambos os autores definem a memória como uma construção do passado realizada no presente. Ela seria, então, variável, e também múltipla, pois cada grupo cultiva um conjunto particular de recordações. Por fim, Pollak e Halbwachs apontam o papel fundamental da memória para a criação do sentimento de identidade. Existem, portanto, continuidades importantes na comparação das obras desses autores. Porém, existem também diferenças cruciais, que procuraremos destacar ao longo do trabalho.

Como dissemos, tanto Pollak como Halbwachs definem a memória como um fenômeno coletivo, ou seja, como uma construção social. No entanto, afirmar o caráter coletivo da memória é suficiente para dizer tudo aquilo que ela é na visão de Halbwachs, mas não na perspectiva de Pollak. Para este último, a memória é coletiva, sim: ela tem uma dimensão social, sendo parcialmente herdada pelos sujeitos. Porém, o indivíduo também tem 
suas lembranças, o que contraria a visão de Halbwachs, para quem o social se define em oposição ao individual. Para Pollak, o indivíduo também é capaz de formar e acessar memórias, participando ativamente da construção das recordações dos grupos. O sujeito administra as influências que lhe chegam de fora a fim de construir suas próprias recordações. Sendo assim, ele não se encontra totalmente submetido aos "quadros sociais da memória". De fato, as lembranças dos indivíduos e grupos se organizam em torno de alguns pontos mais ou menos estáveis, que conferem ordem às suas representações. Contudo, o poder de agência dos indivíduos também se faz presente e deve ser considerado.

Segundo Pollak, as memórias - sejam elas individuais ou coletivas - incluem sempre três elementos: acontecimentos, pessoas (ou personagens) e lugares. Os acontecimentos consistem em eventos dos quais uma pessoa pode ter participado diretamente ou não, isto é, que podem ter sido vivenciados "por tabela", a partir do pertencimento do indivíduo a um determinado grupo. Do mesmo modo, as personagens que integram as lembranças de alguém podem efetivamente ter feito parte do seu círculo de convívio, ou podem apenas ter-se tornado conhecidas devido a sua relevância como figuras públicas. Por fim, os lugares que servem de base para o desenvolvimento das memórias de um sujeito podem ter sido realmente freqüentados durante certo tempo, ou podem ter sido incorporados de modo indireto às suas experiências.

Em suma, a constituição de memórias envolve não só experiências vividas diretamente, mas também, experiências herdadas, aprendidas, transmitidas aos indivíduos pelos grupos através do processo de socialização. Vale dizer que, mesmo os acontecimentos, pessoas e lugares que compõem as experiências diretas dos indivíduos e grupos são alterados quando registrados na forma de lembranças, não correspondendo de modo totalmente fiel à realidade. As memórias podem, ainda, envolver elementos que transcendem o espaço-tempo de duração de vida dos indivíduos e grupos, evocando passagens míticas e fantásticas.

Sendo assim, as memórias podem se basear em fatos reais, ou não. O processo de constituição das lembranças dá lugar a invenções, confusões, imprecisões, projeções, e incoerências, o que pode ocorrer de modo deliberado ou não, envolvendo ainda silêncios e esquecimentos, que se dão de modo consciente ou inconsciente. A formação de recordações também não precisa se desenvolver a partir de datas precisas: a memória tende a prevalecer 
sobre a cronologia oficial, apesar de essa última ter ligações com interesses políticos, sendo mais bem informada pela historiografia.

Para Pollak, à semelhança de Halbwachs, a memória contribui para a criação do sentimento de identidade dos indivíduos e grupos. Em sua definição, a identidade é a autoimagem que os indivíduos e grupos constroem para si mesmos e para outros. Ele concebe a identidade a partir de três elementos: 1) unidade física - que se refere ao corpo, no caso dos indivíduos, e ao território, no caso dos grupos; 2) continuidade no tempo e 3) sentimento de coerência. Ao lançar as origens de um grupo no passado, investindo-o de autoridade, a memória serve de base para a construção de uma narrativa coerente sobre sua trajetória, contribuindo para a criação do sentimento de identidade. Essa seria, portanto, a "função" da memória: ela participaria não só da criação do senso de igualdade entre os membros de uma dada coletividade, mas também da demarcação de fronteiras entre os outros.

Memória e identidade têm sempre um caráter relacional, o que pode resultar em conflitos. Ao invés de serem tomadas como essências, Pollak as define como construções sociais - a memória é uma reconstrução do passado realizada a partir dos interesses e preocupações dos grupos e indivíduos no presente. Isso lhe confere um caráter circunstancial e mutável, pois ela se encontra sempre num processo de reinterpretação e mudança. A memória pode variar, mas deve haver sempre algum nível de concordância das novas representações com aquelas já existentes. Uma vez constituídas, as lembranças tendem a realizar um trabalho de conservação em prol da manutenção das representações do grupo. Caso essa continuidade entre o novo e o velho seja rompida bruscamente, uma crise de identidade pode vir a se instalar.

As transformações da memória também podem decorrer das disputas e conflitos entre os diversos grupos. Segundo Pollak, o caráter negociado da memória já pode ser encontrado na obra de Halbwachs, muito embora o autor francês não dedique grande atenção a esse ponto, desenvolvendo seus argumentos em outra direção. Como vimos, Halbwachs destaca a importância dos testemunhos de outros para a formação das lembranças do indivíduo, o que serviria como argumento para a demonstração do caráter coletivo da memória. No entanto, não é qualquer testemunho que pode servir ao processo de constituição de lembranças comuns: 
Para que nossa memória se aproveite da memória dos outros, não basta que estes nos apresentem seus testemunhos: também é preciso que ela não tenha deixado de concordar com as memórias deles e que existam muitos pontos de contato entre uma e outras para que a lembrança que nos fazem recordar venha a ser reconstruída sobre uma base comum. (Halbwachs, 2006, p.39)

Em suma, é necessário que haja algum nível de concordância entre as lembranças do eu e do outro para que elas possam se reforçar e se completar mutuamente, vindo a constituir um patrimônio comum de recordações. Numa só passagem, Pollak identifica o caráter relacional e negociado da memória na obra de Halbwachs, o que implicaria ainda a participação do indivíduo na constituição dessas lembranças. As análises originais de Halbwachs, no entanto, se encaminham num outro sentido.

Para Halbwachs, o que importa é o caráter coletivo da memória, ou seja, a influência dos "quadros sociais da memória" sobre a formação das lembranças dos indivíduos. Para ele, esses quadros servem como pontos referência que organizam as memórias dos grupos - e dos indivíduos, enquanto membros dos grupos -, conferindo estabilidade e coerência às representações coletivas. A memória contribui para a formação de identidades, e isso se dá na medida em que os grupos se constituem como "comunidades de sentimentos". A adesão dos indivíduos aos grupos e às representações coletivas ocorreria no plano afetivo, mas para Pollak, isso mascara os processos de coerção e dominação que estão relacionados à formação das memórias.

Segundo Pollak, a homogeneidade de um grupo, vista por Halbwachs como sinal de funcionalidade, só pode ser entendida como o resultado da hegemonia de um segmento mais poderoso sobre os demais. Como bem afirma Halbwachs, a memória tem um caráter múltiplo, na medida em que cada grupo cultiva um conjunto particular de lembranças. Na visão de Pollak, porém, é justamente essa diversidade que leva a memória a se tornar um objeto de conflitos e disputas, pois os grupos procuram salvaguardar suas visões sobre o passado, impondo-as sobre os demais.

Para Halbwachs, a memória tem caráter seletivo, mas isso ocorre simplesmente porque não é possível registrar todos os eventos do passado. A seletividade da memória seria necessária estritamente por conferir ordem às representações dos grupos. Pollak, por sua vez, 
denomina "enquadramento" a esse processo de escolha que fundamenta a constituição mnemônica: alguns eventos são priorizados em detrimento de outros, mas isso não se dá de modo totalmente aleatório. Indivíduos e grupos procuram destacar os elementos que concorrem para a formação de uma identidade positiva, auxiliando a manutenção de uma posição privilegiada de poder e status - ainda que isso não se dê de modo totalmente consciente e calculado. O processo de "enquadramento" encontra-se na base de formação das memórias de caráter hegemônico, as quais estão relacionadas aos interesses da sociedade englobante.

A elevação das memórias de um grupo ao plano hegemônico envolve o combate e a supressão das memórias de outros grupos, que passam a ocupar uma condição de marginalidade. No entanto, ainda que sofram com a opressão e a censura, esses grupos não deixam de produzir suas próprias memórias. Pollak refere-se a esta modalidade de lembranças como "memórias subterrâneas": são elas as memórias dos grupos marginalizados, das minorias políticas, dos segmentos mais pobres, dos movimentos sociais, etc. Por serem reprimidas, elas tendem a assumir um aspecto traumático, mas ao mesmo tempo é isso o que explica sua força. Se, por um lado, elas se vêem relegadas ao silêncio e ameaçadas pelo esquecimento durante longos períodos, por outro, elas tendem a vir à tona com muita intensidade quando os ventos mudam de direção, rompendo com a ordem vigente e trazendo mudanças e conseqüências incalculáveis.

O silêncio não deve ser visto sempre como um sintoma do risco de amnésia coletiva. Muitas vezes, ele se mostra como uma condição necessária para a sobrevivência das lembranças de grupos subjugados. Por se encontrarem à margem, essas memórias não têm como se conservar e se propagar através dos meios oficiais de expressão. Ainda assim, elas sobrevivem, como forma de resistência política e cultural. Nesse caso, a memória, enquanto construção idealizada do passado que se faz no presente, pode ser entendida como uma forma de contestação da ordem vigente e como a formulação de um projeto social para o futuro.

As memórias subterrâneas tendem a sobreviver e a transmitir-se por vias informais, como redes de sociabilidade que abrangem o âmbito da família ou de pequenos grupos, sempre com uma tonalidade afetiva mais acentuada. Elas tendem a carregar também a marca 
da oralidade, por isso, as entrevistas de história oral, ou história de vida, se apresentam como um método privilegiado para a abordagem desse tipo de experiência.

A história oral visa à reconstituição dos eventos a partir de memórias baseadas em relatos individuais. Nesse caso, os testemunhos pessoais são considerados relevantes, primeiro, porque o sujeito é tomado como o representante de determinado grupo marginalizado, sintetizando em sua trajetória particular as vicissitudes do caminho percorrido pelo grupo. No entanto, o indivíduo também tem suas próprias recordações: ele administra suas lembranças, procurando harmonizá-las com a identidade que almeja construir para si mesmo. Tal como os grupos, os indivíduos intentam, igualmente, elaborar uma narrativa coerente sobre suas trajetórias de vida, produzindo algo semelhante ao sentimento de unidade subjetiva que Bourdieu (1998) denomina "ilusão biográfica". Essa tendência se torna mais acentuada na situação artificial criada pela entrevista, quando o sujeito se vê obrigado a elaborar representações sobre si mesmo de modo reflexivo.

De todo modo, o que desejamos destacar nesse ponto é a existência de um "trabalho psicológico" fundamental, realizado pelos indivíduos, na base do processo de formação das memórias. As situações vivenciadas pelo grupo são elaboradas internamente pelos indivíduos, que criam suas próprias visões e interpretações sobre os eventos. Pollak destaca, portanto, a importância da agência individual para a formação das lembranças e procura conectar os planos micro e macro da vida social em sua análise, mostrando que a estrutura se constitui, se expressa e se modifica no plano da ação individual.

\section{Beatriz Sarlo e os limites da subjetividade.}

No longo debate que separa memória e história como modalidades diferentes de reconstituição do passado, podemos dizer que Beatriz Sarlo se localizaria do lado da história. Ou melhor, diante da importância exagerada assumida pela memória e pelos testemunhos pessoais como fontes de verdade, desde o surgimento da história oral como um campo de estudos legítimo no meio acadêmico, a autora procura apontar os limites da subjetividade como fonte de conhecimento, destacando a importância do rigor metodológico para a manutenção do estatuto científico da história. Recorrendo ao pensamento de Susan Sontag, 
ela afirma: "é mais importante entender do que lembrar, embora para entender também seja preciso lembrar" (Sarlo, 2007, p.22).

No livro Tempo passado (2007), Sarlo critica aquilo que ela mesma denomina "guinada subjetiva", processo que teria ocorrido nas ciências sociais ao mesmo tempo em que a chamada "guinada lingüística", por volta das décadas de 1970 e 1980. Nesse contexto, as ciências sociais passaram a se ocupar da subjetividade como objeto de estudos, numa atitude reflexiva que procurava problematizar as abordagens mais tradicionais da disciplina, questionando as variadas formas de determinismo que faziam do indivíduo um mero autômato, um ser passivo diante das diversas influências recebidas do meio externo. Com a valorização da ação individual, as ciências sociais corrigiam um equívoco do passado, reconhecendo a existência de um sujeito que desfruta de certa margem de liberdade e contribui para a construção da vida social. No entanto, esse avanço abriu espaço para que o indivíduo, alijado pela sociologia no momento inicial de constituição como ciência, voltasse a ocupar um papel central no cenário epistemológico.

No campo da história, a guinada subjetiva pode ser observada a partir do surgimento de novos objetos, métodos e campos de pesquisa, tais como a história oral ou história vida, a nova história, a história contemporânea ou história do tempo presente, etc. Com a influência da abordagem de tipo etnográfico, alguns pesquisadores promoveram o fortalecimento de áreas ligadas à história social e cultural, interessando-se pelos aspectos "micro" da vida coletiva. Os estudos históricos passam, então, a se ocupar de pequenos grupos, das relações familiares e comunitárias, de comportamentos desviantes, das minorias marginalizadas e, ao mesmo tempo, da conduta do "homem comum", definido em oposição aos grandes nomes da cena pública. Nessa esteira, temos a valorização da subjetividade, das emoções, dos interesses e vontades individuais, dos impulsos irracionais ou inconscientes como fontes do conhecimento e como elementos imprescindíveis ao bom entendimento do comportamento humano em todas as épocas e lugares.

Com a história oral, observamos a valorização da memória e dos relatos em primeira pessoa como fontes de verdade e meios privilegiados para a reconstituição histórica do passado. A premissa que sustenta esse modo de fazer história aponta a memória como o resultado de uma experiência mais verdadeira, por ela ter sido pretensamente vivenciada de 
forma direta ou imediata - não-mediada - pelo indivíduo. O modo mais apropriado para a captação dessas memórias seriam os testemunhos pessoais, ou seja, os relatos orais em primeira pessoa, nos quais os entrevistados procuram reconstituir as ricas experiências plenas de realidade vivenciadas por eles.

De certo modo, a concepção da memória como o resultado de um certo tipo de experiência direta já se encontra presente no pensamento de Halbwachs (2006). Esse autor valoriza as lembranças como um fator de coesão social, definindo-a como o fruto de experiências espontâneas que permanecem vivas na ação dos grupos no presente, enquanto a história seria caracterizada pela frieza de um registro escrito e artificial sobre fatos que já não movem mais os homens. Devemos destacar, no entanto, que as lembranças são estritamente coletivas em sua perspectiva, não comportando qualquer dimensão subjetiva.

Benjamin (1987), por sua vez, aponta uma relação de identidade entre experiência e relato, que encontra seu paradigma na figura do "narrador", mas que teria se tornado impossível na modernidade. Na antiguidade e na idade média, o narrador seria capaz de comunicar a vivacidade de sua experiência subjetiva de modo mais pleno, dirigindo-se diretamente a um público que se enriquecia espiritualmente ao ouvir seus relatos. Isso mudou, no entanto, como o surgimento da imprensa e do romance na modernidade, quando a figura do narrador tornou-se dispensável. Nos tempos modernos, a experiência traumática do choque torna-se parte do cotidiano, fazendo com que os homens comuns, tal como os soldados que retornam da guerra, tenham dificuldades de constituir experiências. Ou seja, eles não conseguem torná-las inteligíveis nem para si mesmos nem para os outros, e assim elas se perdem no silêncio. Ainda assim, a obra de Benjamin é marcada por uma aporia, na medida em que ele defende a importância da memória como uma forma de conhecimento superior ao positivismo da "história monumental", realçando seu poder de reparação.

Sarlo não contesta a importância da memória e do testemunho, em si mesmos, como fontes de conhecimento para os estudos históricos. O problema são os exageros ligados à guinada subjetiva, que fazem com que elas assumam a condição de fontes inquestionáveis e infalíveis na reconstituição do passado, como se fossem mais reais e verdadeiras que as demais. Para a autora, as lembranças e relatos pessoais podem, sim, contribuir para a construção do conhecimento histórico, desde que suas especificidades sejam levadas em 
consideração. Memórias pessoais podem ser fontes valiosas em determinados contextos de pesquisa, mas isso não pode ser aplicado a todas as situações. Como toda metodologia, a história oral tem suas vantagens e limitações, e assim os testemunhos devem ser submetidos a uma avaliação crítica.

A autora também destaca a importância política que os testemunhos podem assumir em certos contextos históricos, quando a memória se torna uma fonte alternativa diante das visões oficiais defendidas pelos grupos que se encontram no poder. No caso da América Latina, os relatos pessoais das vítimas-testemunhas foram fundamentais para denunciar os abusos cometidos pelas ditaduras civil-militares que dominaram o continente entre as décadas de 1960 e 1980, contribuindo para a transição democrática nesses países. Os testemunhos têm ainda um caráter reparador e terapêutico para a subjetividade das vítimas de regimes autoritários e tragédias como o holocausto, cumprindo importante função moral e jurídica. $\mathrm{O}$ problema, na visão da autora, é quando os direitos morais atribuídos à memória levam seus adeptos a reivindicarem um estatuto indevido de veracidade. Toda fonte de conhecimento pode e deve ser criticamente analisada, e com os relatos pessoais não deve ser diferente.

Para Sarlo, a importância moral assumida pelos testemunhos das vítimas de casoslimite, como o holocausto, passou a ser estendida de modo indevido a toda forma de experiência subjetiva, inclusive às mais banais e ordinárias. Como diz a autora, "vivemos uma época de forte subjetividade", e esse traço não é uma exclusividade do campo da história ou das ciências sociais. Trata-se de uma característica cultural e ideológica das sociedades ocidentais contemporâneas. O mundo ocidental assiste à invasão do espaço público pelos assuntos da vida privada, num processo ao qual Sennett (1988) denomina "tirania da intimidade". Nesse contexto, temos o declínio do "homem público" e a emergência do "sujeito narcísico" como tipo social, um modelo de conduta que leva o indivíduo a se enclausurar e se afogar nas profundezas de si mesmo.

Richard Sennett critica o narcisismo contemporâneo, encarando-o como uma forma de incomunicabilidade que leva à erosão da vida coletiva. Apesar da desconfiança de alguns intelectuais "pessimistas", vivemos aparentemente numa época de "otimismo identitário", como afirma Sarlo. Assim, numa visão mais difundida, o sujeito não só é capaz de constituir experiências, como também é capaz de expressá-las plenamente aos outros. Numa época em 
que se desconfia da Verdade oferecida por qualquer modelo de meta-narrativa, seja ela mística ou secular, acreditamos na existência de verdades múltiplas, que têm sua origem na experiência parcial e impressionista do sujeito.

Contra a valorização exagerada da subjetividade, Sarlo opõe a noção de que a memória, bem como toda experiência tida como puramente subjetiva, apresenta um caráter discursivo. Desse modo, as lembranças só se constituem quando assumem a forma de uma narrativa, organizando os acontecimentos da vida pessoal em torno de princípios teleológicos bem definidos, que transcendem o indivíduo e conferem um sentido socialmente inteligível às trajetórias individuais. Para a autora, portanto, não existe uma experiência pura, verdadeira e plena que se deixe expressar por inteiro através dos testemunhos individuais. Não existe uma relação de identidade entre o relato e a experiência, assim como não existe uma relação referencial entre as palavras e as coisas na teoria foucaultiana (Foucault, 2002) . Em suma, o relato remete sempre a uma experiência anterior, mas ao mesmo tempo, a experiência não existe caso não seja expressa e formatada por um relato, sendo inserida na ordem de determinado discurso.

Como vimos, a memória é uma reconstrução do passado que se realiza no presente. Sendo assim, ela tem sempre um caráter vicário e fragmentário, pois lida com experiências e sujeitos que se encontram necessariamente ausentes no momento em que o relato é produzido. A hegemonia do presente e o anacronismo são traços que marcam toda forma de conhecimento sobre o passado, o que pode ser aceito no caso da memória, mas deve ser problematizado no âmbito da historiografia. As memórias e relatos pessoais são importantes, mas não são o único caminho que nos leva ao passado, tampouco o mais confiável.

\section{Considerações finais}

Desenvolvo agora alguns comentários gerais sobre o que foi discutido ao longo desse trabalho. No que diz respeito à discussão sobre a relação entre memória coletiva e memória social, podemos apontar a perspectiva de Halbwachs como a mais extremista na defesa do caráter social das lembranças. Para ele, a memória é coletiva, e isso resume tudo o que há de 
mais importante a ser dito sobre ela. As recordações dos indivíduos se formam a partir dos quadros sociais fornecidos pelos grupos dos quais eles participam - não há espaço para a manifestação da subjetividade ou da singularidade individual. A liberdade do sujeito é uma ilusão que se forma diante da impossibilidade de atribuição das razões de seu comportamento a uma só corrente social. Em suma, não há memória que seja puramente individual, os indivíduos não capazes de formar lembranças próprias, nem participam de modo ativo na constituição da memória coletiva - eles participam, sim, desse processo, mas não apresentam sinais de reflexão ou agência.

Pollak, por sua vez, retoma e problematiza a perspectiva de Halbwachs sobre a constituição da memória. Ele destaca o caráter negociado e potencialmente conflituoso do processo de formação das lembranças, apontando a existência de memórias hegemônicas e subalternas - ou melhor, subterrâneas, subversivas, revolucionárias. Por serem reprimidas durante longos períodos, essas lembranças carregam um aspecto traumático, irrompendo com uma força incontrolável quando as condições se mostram favoráveis. Devido ao seu caráter marginal, esse tipo de recordação sobrevive através de canais informais de transmissão, sendo marcado pela oralidade. Assim, a história oral se apresenta como um método valioso para a construção do conhecimento sobre o passado, partindo das memórias individuais como via de acesso para a reconstituição das memórias dos grupos. Para Pollak, a memória é coletiva, mas isso é apenas uma parte do que ela é. Os indivíduos também têm suas lembranças: através de uma espécie de "trabalho psicológico", eles elaboram subjetivamente os acontecimentos, participam ativamente do processo de formação das memórias dos grupos e administram suas próprias lembranças em harmonia com a identidade que almejam construir para si mesmos. Pollak reconhece, portanto, o poder de agência dos sujeitos e a importância das práticas individuais para a constituição, mudança e atualização das estruturas sociais.

Por fim, Beatriz Sarlo procura apontar os limites da subjetividade como fonte de conhecimento, tendo em vista a importância indevida assumida pela memória e pelos testemunhos pessoais como fontes de uma verdade inquestionável, baseada no imediatismo da experiência individual. Essa tendência pode ser encontrada na hipervalorização da história oral como método de reconstituição do passado. Quando Pollak defendeu a história de vida como forma de acesso às memórias de grupos marginalizados, os estudos históricos passavam por um momento de importantes transformações, que levaram ao englobamento da memória e 
da subjetividade como fontes de conhecimento. Sarlo, no entanto, escreve numa outra época, marcada pela invasão cada vez mais agressiva do plano público pelos assuntos da vida privada. Nesse sentido, ela procura desfazer a pretensa identidade estabelecida entre experiência e relato pessoal, mostrando que a memória tem sempre um caráter discursivo e se forma como uma narrativa orientada por princípios sociais.

Em suma, o que procuramos mostrar nesse artigo é que a memória apresenta de fato um caráter coletivo que não pode ser negado. No entanto, isso não significa que o indivíduo se encontre totalmente alijado do processo de formação de lembranças. O sujeito tem suas próprias recordações, assim como também desfruta de certo nível de liberdade, consciência e poder de ação em todos os níveis da vida social. A memória não é totalmente coletiva, nem tampouco totalmente individual. A consideração do poder de agência dos indivíduos nos permite observar a articulação entre indivíduo e sociedade, ação e estrutura, numa dialética que evidencia que os planos micro e macro-sociológicos são complementares e não podem ser entendidos de modo isolado.

\section{Referências Bibliográficas:}

BENJAMIN, Walter. "O narrador". In: Walter Benjamin - Obras escolhidas, vol. 1: Magia e técnica, arte e política. São Paulo: Editora Brasiliense, 1987.

BOURDIEU, Pierre. "A ilusão biográfica". In: AMADO, Janaína; FERREIRA, Marieta de Moraes (org.). Usos e abusos da história oral. Rio de Janeiro: Editora FGV, 1998.

DURKHEIM, Émile. As regras elementares do método sociológico. São Paulo: Nacional, 1984. . As formas elementares da vida religiosa. São Paulo: Martins Fontes, 1996. . O suicídio. São Paulo: Martins Fontes, 2000.

FOUCAULT, Michel. As palavras e as coisas. São Paulo: Martins Fontes, 2002.

HALBWACHS, Maurice. A memória coletiva. São Paulo: Ed. Centauro, 2006._.

POLLAK, Michael. "Memória, Esquecimento, Silêncio". Revista Estudos Históricos, Rio de Janeiro, v. 2, n. 3, 1989. . "Memória e identidade social". Revista Estudos Históricos, Rio de Janeiro, v. 5, n. 10, 1992. 
SANTOS, Myrian Sepúlveda dos. Memória coletiva e teoria social. São Paulo: Annablume, 2003.

SARLO, Beatriz. Tempo passado: cultura da memória e guinada subjetiva. São Paulo: Companhia das Letras, 2007.

SENNETT, Richard. O declínio do homem público. São Paulo: Companhia das Letras, 1988.

COLLECTIVE MEMORY AND INDIVIDUAL REMEMBRANCES ACCORDING TO THE PERSPECTIVES OF MAURICE HALBWACHS, MICHAEL POLLAK E BEATRIZ SARLO

\begin{abstract}
In this article, I discuss the relationship between collective memory and individual memory according to three different perspectives. Maurice Halbwachs founded the memory studies within the social sciences, conceiving it entirely as a collective phenomenon. Pollak problematizes this view, pointing the negotiated aspect of memory and the importance of individual agency for its formation. Finally, Sarlo indicates the limits of subjectivity as a source of knowledge and highlights the discursive aspect of the mnemonic constitution. In short, memory is not entirely social nor totally individual: structure and practice are intertwined in the construction of memories.
\end{abstract}

KEYWORDS: collective memory; individual remembrance; agency. 